\title{
Why Psychotherapy never picked up in India : Could there be a solution?
}

\author{
Dr. Devashish Konar ${ }^{1}$ \\ ${ }^{1}$ Consultant Psychiatrist
}

India as a nation has always been interested in matters of mind. In fact volumes of ancient Indian writings are dedicated to the understanding of human mind. Why then psychotherapy, which is a healing art through talking, never gained popularity in India. Psychiatry that we practice in India, is completely an imposed western model based discipline. Whatever is medicine and technology based is easy to match. But talk therapy which is completely culture specific cannot be simply copied from other culture. Indian mind is different as is mind of any other culture. First let us forget all western models of talk therapy and build up a model which is typically Indian. Because we train people in alien models, we do not develop into good therapists barring few who can adapt.

From childhood to school to college to medical school I learned to talk according to my own culture in my own way. Suddenly while being trained for psychiatry new rules for talk were taught by my professors who considered many of these dictums as if from Bible. I found them very cumbersome and had to do lot of hard work to try to assimilate them in my work.In spite of being trained for three years in that language I never felt comfortable with the concepts.

I used to try to practice as taught in our psychotherapy class. Then luckily I got chance to work for some period in England and I found how different the society is culturally and then I understood why their concepts don't work with our patients. For

\section{Corresponding Author:}

Consultant Psychiatrist

Mental Health Care Centre, Burdwan \& Kolkata, West Bengal example, anxiety of our patients decrease by our touch whereas there people may become anxious by touch. My teacher in India used to teach me what should be the minimum distance with the patient while making a sitting arrangement for therapy which I found so relevant with patients there which I always used to feel so unimportant with patients in India.

Diseases can never be understood only in terms of molecular biology. Disease is also a complex human experience, which manifests differently in accordance with his or her experience, philosophy, and expectation. You can never reach a person completely and provide him with adequate relief if you are not able to grasp the total perspective of the illness. By now we have enough evidence that psychotherapy does give rise to brain changes, which help, in symptom amelioration and recovery. Then the question is why we are not yet able to use it as an important therapeutic tool in Indian context?

Let us look for possible causes. Cost has always been blamed as prohibitive factor. If doctors' consultation is tagged with talk therapy, in a structured manner, psycho education, principles of cognitive therapy, family therapy, use of culturally appropriate anecdotes, advising on appropriate life style related issues, reassuring and infusing positive thinking, we can have cheaper models. Many of us unnecessarily feel guilty that we are not doing talk therapy. In fact we all have been practicing it. What we need is formalising it consciously.

Many a time we are doing psychotherapy without being aware. Psychoeducation, using principles of cognitive behaviour therapy, yoga meditation mindfulness based CBT, use of culturally appropriate 


\section{Why psychotherapy never picked up in India?}

anecdotes, advising on appropriate life style related issues, family therapy, all improve treatment outcome. Finally youcan't afford to forget that psychotherapy is all about healing relationship.

From student days we haveheard that psychotherapy is not common in our place because there aren't many trained people. For every other branch of medicine you have enough number of trained people, why not in this area. To paraphrase it why did people not bother to learn this art. Is it that the training did not appeal to people? Possibly yes, when you don't find it compatible with your own mind frame, you simply lose interest.

You need to think indigenous. India as a nation has always been interested in matters of mind. In fact volumes of ancient Indian writings are dedicated to the understanding of human mind. Why then psychotherapy, which is a healing art through talking, never gained popularity in India. Whatever is medicine and technology based is easy to match. But talk therapy which is completely culture specific cannot be simply copied from other culture. Indian mind is different as is mind of any other culture. First let us forget all western models of talk therapy and build up a model which is typically Indian. Because we train in alien models, we do not develop into good therapists barring few who can adapt.

It is high time to get rid of western models. With fading colonial hangover and India earning a respectable place in globalised economy we are gaining confidence in having our own models of development in every field. Why psychotherapy be an exception? Indigenous psychotherapeutic models must be developed which should suit Indian patients and doctors both.

Colonial baggage is a liability. Modern Psychiatry started in India in an era when we were under colonial rule. You may argue that even other specialisations started during same period. So why mention this? Talk therapy is highly culture specific. Other treatments of modern medicine, be it with drugs or surgery are not so culture specific.
We need to start where Indian masters left. If Indian psychiatrist are serious about psychotherapy it has to be indigenous which will suit Indian Psychiatrists as well as Indian Patients.For that they need to read our own people like Girindra Sekhar Bose, Surya, Neki, N.N. Wig, Venkoba Rao and Ajita Chakraborty who have made some basic suggestions about how to give talk therapy to our Indian patients.

Dependency in India has a different meaning altogether. Family is a useful tool in the treatment. The Indian Guru Chela relationship can be a model for psychotherapy. Indian culture idealises individual submergence in complex interdependence and in my opinion we should not be ashamed of it.

There are important cultural differences from west. From ancient time there is permissiveness in Indian Society. In Indian society nothing is as devastating. Indian existential approach has a great tradition. Dissociation and detachment as taught by Indian culture has lot of potential as being a way of life.

Our own models need to be learnt. There has been talk about Bhagvat Geeta Model by Venkoba Rao. Gita is a good psychotherapeutic tool for Indians. It is so much in every day's talk of Indians that taking it up in time of crisis is simple and easy. Then there is Guru Chela (Teacher Student) Model by Neki which talks of dialectical relationship of wisdom between teachers and students, the guru shishyaparasparyam. Family therapy model by Vidyasagar has been a major source of inspiration for people trained under him.

While talking to patients it is very good to talk with anecdotes from Indian epics and stories from Upanishads which are actually embedded in the consciousness of Indian mind. The whole Upanishads are meant for bestowing peace of mind by answering fundamental questions of life. Everything may not be as relevant today but essence and methods may still be relevant.

To give you an example Indians have their own ways of dealing with bereavement. If you are talking to a 


\section{Why psychotherapy never picked up in India?}

person who is presently bereaved, there are some of the concepts like indestructible soul, rebirth etc. These are common in Indian thinking and they are very much reassuring to the person. They do get resolved over time by themselves. If you contradict and try to self-actualize the person prematurely you will be unnecessarily disturbing the harmony of bereavement resolution.

Yoga has long been a neglected area even in our own continent. Many of our patients knowabout Yoga and Pranayam (breathing exercises), you just need to reassert to them to practice those. Those who do not know can learn it easily with little training.Jacobson's relaxation, in contrast, become mechanical for them and in few days they don't continue. Recently WHO has taken up yoga in a big way and India is an important partner.
Lastly, to be viable, existing psychotherapy protocols need to be made briefer, culturally appropriate and more efficient for improved acceptance and widespread implementation. And then you need formal training of psychologists in more number who can take up talk therapy as their career. In India Psychiatrists are so few in number that they will never have so much time for separate talk therapy sessions. On the other hand whole lot of people who study psychology till universities go a waste serving in some administrative or clerical job, who could have been jolly well trained into clinical psychologists serving society as talk therapists. Equally important is to have proper licensing authority who will decide who all can practice talk therapy. 